\title{
TOCQUEVILLE Y EL POPULISMO
}

\section{Tocqueville and populism}

José Antonio Aguilar Rivera ${ }^{1}$

Fecha de recepción: 21 de septiembre del 2018

Fecha de aceptación: 06 de abril del 2019

1- Nacionalidad: Mexicana. Grado: Doctorado. Especialización: Ciencias política. Adscripción: Centro de Investigación y Docencia Económicas, A.C. . Correo electrónico: joseantonio.aguilar@cide.edu. DORCID: http://orcid.org/0000-00019250-0827 


\section{Resumen}

Este trabajo analiza la perspectiva de Alexis de Tocqueville sobre el populismo en dos momentos y lugares específicos: su viaje a América a principios de la década de 1830 -el cual coincidió con la presidencia de Andrew Jackson-y la revolución de 1848 en Francia -que el autor recuenta en sus Souvenirs-. Discutir la relación entre Alexis de Tocqueville y el populismo se antoja anacrónico. Sin embargo, los componentes centrales del populismo - como la apelación directa al pueblo, el líder carismático, la polarización ideológica que lleva a dividir el mundo entre amigos y enemigos, etc. - le eran conocidos a Tocqueville y a sus contemporáneos. En términos generales, la política populista contemporánea sería probablemente reconocida por los hombres del siglo antepasado como una peculiar forma de demagogia. ¿Cómo se enfrentó Tocqueville al fenómeno de la política demagógica en su tiempo? Podemos adivinar con cierta facilidad que su posición frente a los demagogos fue crítica. Sin embargo, podemos preguntarnos sobre las razones de esa oposición y sobre el entendimiento que Tocqueville tenía del liderazgo, los fundamentos y las consecuencias de lo que hoy podríamos reconocer como populismo.

Palabras clave: Alexis de Tocqueville, populismo, La democracia en América, revoluciones de 1848 .

\section{Abstract}

This paper analyzes Alexis de Tocqueville's perspective on populism in two different places and moments in time: his trip to America at the beginning of the 1830s-which coincided with Andrew Jackson's presidency-and the revolution of 1848 in France - which Tocqueville recounts in his Souvenirs. Discussing the relation between Tocqueville and populism may seem like an anachronism. However, the main components of populism-such as the direct appeal to the people, the charismatic leader, the ideological polarization that divides the world in friends and enemies, among others-were well-known to Tocqueville and his contemporaries. In general terms, contemporary populist politics would have been called demagogic during the nineteenth century. How did Tocqueville face demagogic politics during his time? It is easy to say that he was critical of demagogues. However, we can ask about the reasons for this criticism, as well as about Tocqueville's understanding of what we would today call populist leadership and its consequences.

Keywords: Alexis de Tocqueville, populism, Democracy in America, revolutions of 1848 . 
“...no estábamos más ciertos del Presidente que de la mayoría. Ciertamente, para nosotros y para la República, Luis Napoleón era el mayor de los peligros y el más cierto".

Alexis de Tocqueville, Souvenirs

\section{Introducción}

- Por qué los liberales, incluso los de izquierda, son críticos del populismo? ¿Qué es el populismo? ¿ Como señala Paulina Ochoa, "la ideología populista adopta una distinción maniquea entre el pueblo y las élites y apela directamente a la 'voluntad general' del pueblo para legitimar sus pretensiones rehusándose a conceder autoridad a las instituciones cuando sus decisiones se encuentran en conflicto con la voluntad popular" (Ochoa, 2015: 62). ${ }^{2}$ Los liberales democráticos miden la voluntad popular a través de instituciones estatales y aceptan las limitaciones constitucionales.

En línea con Ochoa, para Jan-Werner Müller los populistas se caracterizan por su intención de representar al "pueblo verdadero" - un "pueblo real" - en oposición a uno o varios segmentos de la población que, por oposición, pertenecen al pueblo no verdadero, como las élites o las minorías étnicas (Müller, 2016: 27). Más aún, los populistas se dicen capaces de determinar cuál es el bien común al que dicho pueblo verdadero aspira. No se trata, especifica Müller, del deseo popular expresado en las urnas. Al contrario, se trata de un bien común intangible - una suerte de "voluntad general" - imaginada como el deseo último de la nación, que el líder populista y sus seguidores conocen y que puede no corresponder a un resultado electoral determinado. Los líderes populistas quieren ver el deseo de la nación alcanzado y, por lo tanto, acusan a las instituciones electorales cuando los resultados que éstas sancionan no corresponden a los que la nación en "realidad desea". Es lo que ha ocurrido en Hungría con Victor Orbán, en México con López Obrador, en los Países Bajos con Geert Wilders y en Estados Unidos con Donald Trump (Müller, 2016: 32). Cuando los resultados electorales les son contrarios, es porque la nación "no ha hablado" o porque las elecciones están arregladas.

Müller arroja luz sobre un elemento más del actuar populista: la producción de la moralidad. La línea que se traza entre el pueblo verdadero y el no verdadero es una línea moral. Esta distinción permite agrupar a grupos radicalmente distintos que, por su inmoralidad, quedan excluidos del pueblo verdadero. Müller ejemplifica esta idea con la "relación simbiótica" que trazaba Andrew Jackson entre los "aristócratas" estadounidenses, los nativos americanos y los esclavos. Los tres grupos, ya fuera porque eran parásitos del trabajo de otros, o porque resultaban marginales al americano común y corriente, podían denunciarse como inmorales (Müller, 2016: 23).

Finalmente, Müller distingue al populismo del pluralismo. Más allá del trazo moral de un pueblo verdadero, que es contrario a las élites y a grupos marginales, el populismo se caracteriza por la postura antipluralista

2- Al respecto, véase también Aguilar Rivera (2013). Agradezco a Óscar Godoy por invitarme a impartir la Cátedra Tocqueville en la Universidad Adolfo Ibáñez, Santiago de Chile, en el 2017. Este ensayo tuvo como origen el texto presentado en esa ocasión. Agradezco la ayuda en la preparación de este trabajo de Carlos Arroyo y los comentarios de dos revisores anónimos. 
de que "ellos, y sólo ellos, representan al pueblo" (Müller, 2016: 20). En oposición a la idea de que hay intereses variados que contienden entre sí, el populismo se apega al "holismo", la idea de que el cuerpo político no debe estar dividido; sólo tiene un representante verdadero (Rosenblum, cit. por Müller, 2016: 20). Esta idea apoya la noción, mencionada arriba, de que quienes no apoyan al verdadero representante - o a la "voluntad general" imaginada - no pertenecen en realidad al pueblo. El cuerpo político ideal excluiría necesariamente a estos elementos y, por lo tanto, no requeriría de la representación pluralista de intereses.

Es cierto, como propone Laclau, que los intentos por explicar el populismo a veces lo relegan al ámbito de lo irracional. El populismo parece comprenderse como "el simple opuesto de formas dignificadas con el estatus de una verdadera racionalidad" (Laclau, 2006: 34). Sin embargo, el populismo también es una racionalidad política que puede delimitarse de acuerdo a los supuestos propuestos por Ochoa y Müller; es un intento antipluralista de afirmar que se representa al pueblo "moral" verdadero, en contraposición a miembros inmorales - y, por lo tanto, no verdaderos - de dicho pueblo.

Discutir la relación entre Alexis de Tocqueville y el populismo se antoja anacrónico. El fenómeno sociológico que conocemos como populismo no existía en la primera mitad del siglo XIX. Sin embargo, sus componentes centrales le eran conocidos a Tocqueville y a sus contemporáneos. La apelación directa al pueblo, el líder carismático, la polarización ideológica que lleva a dividir el mundo entre amigos y enemigos, etc. eran elementos que bien podían reconocer. Un precursor clásico de ese tipo de política era el cesarismo: la apelación de César al pueblo de Roma en contra de los patricios del Senado que llevó al fin de la república. En términos más generales, la política populista contemporánea sería probablemente reconocida por los hombres del siglo antepasado como una peculiar forma de demagogia. En El Antiguo régimen Tocqueville reconoció que las bases igualitarias que permitirían un discurso igualitario al momento de la Revolución databan de muchos años atrás (Tocqueville, 2004: 108-113). La centralización política y el acortamiento de las distancias entre los antiguos estamentos sentaron las bases para que las apelaciones al "pueblo" tuvieran sentido y fueran atractivas. La pregunta es: ¿cómo se enfrentó Tocqueville al fenómeno de la política demagógica en su tiempo? Su posición frente a los demagogos, podemos adivinar con cierta facilidad, fue crítica. Sin embargo, podemos preguntarnos sobre las razones de esa oposición y sobre el entendimiento que Tocqueville tenía del liderazgo, los fundamentos y las consecuencias de lo que hoy podríamos reconocer como populismo. La pesquisa puede llevarse a cabo en dos espacios físicos y temporales distintos. El primer encuentro - analizado y reflexionado - con la política populista ocurrió en su célebre viaje a América a principios de la década de los 1830. Ahí Tocqueville se topó con el presidente norteamericano Andrew Jackson. El análisis de Jackson y la política jacksoniana revelan mucho sobre la atalaya desde la que miraba Tocqueville, no sólo a los Estados Unidos, sino al mundo. En segundo lugar, la revolución de 1848 en Francia lo colocó en una posición privilegiada: como actor directo de los acontecimientos que dieron al traste con la Monarquía de Julio y como agudo observador de la política. Los Souvenirs ofrecen una entrada no sólo a la sensibilidad aristocrática de Tocqueville sino a una forma de entender la revuelta popular y su relación con el liderazgo y la ideología.

\section{Crítica de la política plebeya: Andrew Jackson y los Estados Unidos}

El viaje de Alexis de Tocqueville a América produjo una notable obra sociológica que impulsó a la fama a su autor: La democracia en América. El acertijo que intrigaba a Tocqueville era: ¿por qué el gobierno 
representativo en ese país, a diferencia de Francia o las nuevas repúblicas hispanoamericanas, sobrevivía y florecía? Estaban en boga variopintas explicaciones: desde las geográficas hasta las raciales. Ninguna convencía al funcionario público con licencia, que tenía menos de treinta años. Las instituciones políticas de ese país le parecieron notables, pero ahí tampoco encontró la clave de su excepcionalismo. La razón estaba en otro lugar: en las costumbres de individuos que se asemejaban mucho entre sí. La igualdad, descubrió, había proahijado singulares hábitos que hacían posible - pero que también amenazaban — a la democracia en los Estados Unidos. El momento político que vivía ese país cuando lo conoció Tocqueville es significativo. Estaba en la presidencia un político populista: Andrew Jackson.

La igualdad de condiciones que Tocqueville encontró en Estados Unidos presentaba un riesgo a la libertad: la tiranía de la mayoría. Ésta podía tener diversas manifestaciones; algunas noveles y otras más tradicionales. Entre estas últimas estaba el "yugo de uno solo" (Tocqueville, 1978: 310). La relación causal entre la igualdad y el despotismo elaborada en La democracia en América está predicada así: "ahora bien, no sé más que dos maneras de hacer prevalecer la igualdad en el mundo político: hay que dar derechos iguales a cada ciudadano o no dárselos a ninguno. En cuanto a los pueblos que han llegado al mismo estado social que los angloamericanos, es muy difícil percibir un término medio entre la soberanía de todos y el poder absoluto de uno solo" (Tocqueville, 1978: 72). Según Tocqueville, en tiempos democráticos desaparecen las diferencias entre los individuos y al mismo tiempo desaparecen los cuerpos intermedios que en el Antiguo Régimen servían como "amortiguadores" (entre ciudadanos y gobierno) para evitar el despotismo. Los individuos democráticos son vulnerables a la opresión porque están atomizados, separados unos de otros. Se encuentran a la merced tanto de mayorías tiránicas como de gobiernos centralizados con un gran poder sobre ellos y sin nada que los proteja.

Richter señala que Tocqueville, como Weber, reconoció en Bonaparte el fenómeno del carisma. Tocqueville señaló cómo las atractivas características personales de los líderes carismáticos "pueden servir, y a menudo han servido, como excusas políticas para que los súbditos rindan un obediente servicio a sus amos" (Richter, 2006: 262). Como señala Schleifer, el peligro del despotismo se agudizaba en presencia de un héroe militar (le despotisme d' un seul militaire). En efecto, "la principal inspiración de esta idea era, con toda seguridad, Napoleón, pero está claro que Norteamérica fortaleció su convicción. Durante su periplo norteamericano había oído hablar de la incompetencia y corrupción de Andrew Jackson y había leído acerca de sus actitudes demagógicas. Pero Jared Sparks le había dicho que, aunque las personas mejor informadas se opusieran a Jackson, "la mayoría está todavía a disposición del general"' (Schleifer, 1987: 175). En efecto, Tocqueville escribió en La democracia: “¿Cómo negar la increíble influencia que ejerce la gloria militar sobre el espíritu del pueblo? El general Jackson, que los norteamericanos eligieron por segunda ocasión para colocarlo a su cabeza, es un hombre de un carácter violento y de una capacidad mediana. Nada en todo el curso de su carrera había probado que tuviese las cualidades requeridas para gobernar a un pueblo libre. Por eso la mayoría de las clases ilustradas le fue siempre contraria. ¿Quién le colocó en el asiento del presidente, y le mantiene ahí todavía? El recuerdo de una victoria lograda por él hace veinte años, a los muros de Nueva Orleáns. Ahora bien, esa victoria de Nueva Orleáns es un hecho de armas muy ordinario del que no se llegarían a ocupar largo tiempo más que en un país donde no hay batallas; y el pueblo que se deja así arrastrar por el prestigio de la gloria es, aparentemente, el más frío, el más calculador, el menos militar, y si puedo expresarme así, el más prosaico de los pueblos del mundo" (Tocqueville, 1978: 279). 
El personaje claramente intrigaba a Tocqueville. En cierta manera, el fenómeno del héroe militar era poco norteamericano. Y por ello era todavía más relevante para el joven francés. "Esta susceptibilidad", señala Schleifer, "ante el peligro de nuevos Césares (o Napoleones) la mantendría Tocqueville durante toda su vida, e influiría en la forma de la Democracia en América, siendo especialmente aguda después de las penosas experiencias de 1848-1851" (Schleifer, 1987: 176). ¿Era demasiado fácil la explicación del populismo jacksoniano de Tocqueville? ¿Se trataba de una variante contemporánea del ya conocido fenómeno del despotismo militar personalista? La breve entrevista que sostuvieron él y Beaumont con Jackson u Old Hickory, como se le conocía, no despejó sus dudas. No hallaron en él un líder carismático de la calaña de Napoleón (Richter, 1988; Richter, 2006: 262). Jackson era un bicho diferente. Y su relación con la gente también lo era. A Tocqueville le sorprendió que un bostoniano le escribiera a Jackson una carta en papel periódico ofreciéndole un peine de carey. La misiva comenzaba con un simple: "estimado señor" (Brogan, 2006: 152).

La historia del encuentro entre los franceses y Jackson es conocida. Beaumont y Tocqueville llegaron a Washington el 18 de enero de 1832. Los recibió en la Legación francesa el ministro barón Sérurier, un viejo bonapartista recuperado por Luis Felipe. Sérurier había apoyado con entusiasmo la aventura de los dos jóvenes. Al día siguiente de su arribo los llevó a la Casa Blanca a conocer al Presidente (Brogan, 2006: 152). Para Jackson sería solo uno de muchos encuentros. La rutina era: recibía a visitantes distinguidos durante media hora, les ofrecía una copa, charlaba un poco y acto seguido los despedía. No fue distinto con Tocqueville y Beaumont. Predeciblemente el sesentón presidente no los impresionó en lo más mínimo. En los escasos minutos que departió con ellos sólo mencionó lugares comunes. La ocasión, más que el hombre, les sorprendió: "el presidente de los Estados Unidos ocupa un palacio que en París sería mencionado sólo como una buena mansión privada; su interior está decorado con buen gusto, pero de manera sencilla. El salón en el cual recibe a los visitantes es infinitamente menos magnífico que los de nuestros ministros. No tiene centinelas cuidando sus puertas y si tiene cortesanos, éstos no son muy asiduos en sus atenciones ya que cuando entramos al cuarto se encontraba solo, a pesar de ser el día que dedicaba a recibir al público y en el transcurso de toda nuestra visita sólo aparecieron dos o tres personas... hablamos de cosas bastante insignificantes, dio a cada quien una copa de Madeira, la cual le agradecimos llamándolo 'señor', como el primer visitante" (Brogan, 2006: 152). Jackson saludó a todos de mano.

Es indudable que a Tocqueville le desagradaba Jackson. A pesar de que no presenció de primera mano ninguno de los ataques de ira por los que era famoso, había oído suficientes historias sobre Old Hickory para formarse una idea de su carácter. Esa es la tesis de André Jardin. Tocqueville formó muchas de sus ideas políticas sobre Norteamérica a partir de las opiniones de sus amigos patricios. Los bostonianos, gente como Daniel Webster, el ex presidente John Quincy Adams y otros, sentían un horror por el plebeyo y grosero Jackson. Estos hombres constituían el círculo con el cual Tocqueville y Beaumont tenían afinidad en los Estados Unidos. "Al fin”, pues, "habían hallado en Estados Unidos una sociedad la cual a pesar de ser pequeña, estaba dominada por preocupaciones intelectuales, y no pudieron encontrar una mejor fuente de opiniones generales sobre la gente, la vida social y el gobierno de Estados Unidos. Pero esta élite pertenecía a la oposición, le desagradaba el presidente Jackson y a veces lo despreciaba. Debido a que la Democracia en América no tomó en cuenta este sesgo fracasó en discutir algunas tendencias nuevas en la vida norteamericana" (Jardin, 1998: 151). A la Casa Blanca Tocqueville llevó ideas preconcebidas, producto de sus conversaciones con la oposición aristocrática. 
La reacción de Tocqueville frente al populista Jackson es de desagrado, pero no de temor ni de horror. Hay que comparar el retrato de Jackson con el de Blanqui, hablando frente a la Asamblea Nacional en los días tumultuosos de la revolución de 1848: "fue en ese momento que vi a un hombre ponerse de pie y subir a la tribuna y, a pesar de que jamás lo he vuelto a ver, desde aquel entonces su recuerdo me ha llenado de disgusto y horror. Tenía las mejillas marchitas y hundidas, los labios blancos y una mirada enfermiza, maligna y sucia, como un cadáver pálido y mohoso...parecía como si hubiese vivido en la cloaca y acabara apenas de salir. Me dijeron que era Blanqui” (Tocqueville, 1992: 118).

En parte, Jackson no le pareció tan peligroso a Tocqueville por su peculiar lectura de las instituciones políticas norteamericanas. Estaba convencido de que el presidente de ese país era mucho más débil que un monarca europeo y más débil que el poder legislativo en su conjunto. Para él, "nadie se ha atrevido a arriesgar su honor y su vida para convertirse en presidente de Estados Unidos porque el presidente solo tiene un poder temporal, restringido y dependiente" (Tocqueville, 1969: 128). Para Tocqueville el populismo de Jackson sólo era un epifenómeno, atenuado, de un desarrollo general mucho más preocupante: la tiranía de la mayoría. No tenía importancia propia; era el reflejo de la naturaleza de una sociedad igualitaria. El liderazgo personal - esencial en el análisis del populismo- pasaba a segundo término, pues lo realmente importante era domar a la sociedad democrática. En efecto, en su análisis del poder ejecutivo, Tocqueville había afirmado: "el Presidente de los Estados Unidos es sólo un dócil instrumento en las manos de la mayoría. Ama lo que ella ama y odia lo que ella odia. Navega por delante de sus deseos, anticipando sus quejas y cediendo ante sus más mínimos deseos. Los legisladores quisieron que él la guiara, pero es él el que la sigue" (Tocqueville, 1969: 138).

Como se mencionó arriba con respecto a Jardin, diversos críticos de Tocqueville han alegado que su análisis de la presidencia norteamericana en general, y de la presidencia de Jackson en particular, es deficiente si no abiertamente erróneo. Hay, dice Brogan, un tratamiento inadecuado de los partidos políticos. En la Democracia en América Tocqueville no se percató de que a partir de la ratificación de la constitución federal en la sociedad norteamericana se estaba gestando una política de masas articulada por partidos políticos (Brogan, 2006: 160). En particular, no se dio cuenta de las transformaciones en la estructura partidista que Van Buren y el propio Jackson habían llevado a cabo. Jackson había construido una "máquina" política. De la misma manera, Tocqueville subestimó de manera crítica el poder real del presidente norteamericano. En el caso de Jackson, fue incapaz de percatarse de que el ejecutivo, a pesar de su retórica antifederalista, había logrado reunir una gran dosis de poder en la presidencia. Tampoco tomó conciencia de los incipientes movimientos socialistas ni de la proliferación de sindicatos que tuvo lugar a partir de 1825 (Jardin, 1998: 211, 221).

La "mística" de la presidencia, como la llama Brogan, ya era evidente cuando Tocqueville visitó los Estados Unidos (Brogan, 1981: 361). Jackson había expandido notablemente el uso del poder de veto, había amenazado a Carolina del Sur con hacerle la guerra, había despedido simultáneamente a todos los miembros de su gabinete, menos a uno. Había desafiado con éxito al Congreso en su disputa sobre el status del Secretario del Tesoro, había despedido, al momento de tomar posesión, a una décima parte de todos los empleados públicos federales. Es decir, "había demostrado una nueva forma de liderazgo político" (Brogan, 1981: 361). Tocqueville registra la mayoría de estos desarrollos, pero no lo alarman en demasía. Si bien reconoce que la conducta de Jackson podría convertirse en un riesgo para la autoridad federal, no creía que en ese momento existieran las condiciones sociales necesarias para que el general se 
convirtiera en un verdadero déspota. "Se supone", alegaba Tocqueville, "que el general Jackson desea establecer una dictadura en los Estados Unidos, al introducir un espíritu militarista y al extender los poderes del gobierno central de forma peligrosa para las libertades provinciales. Pero en América el momento para esas intentonas, y la época apropiada para ese tipo de hombres, no han llegado aún. Si el general Jackson hubiese querido proceder de esa manera habría seguramente perdido su posición política y habría puesto su vida en peligro así que no fue tan impetuoso para intentarlo" (Tocqueville, 1969: 393). Así, hizo una aplicación particular de su teoría de la presidencia norteamericana: Jackson era "el esclavo de la mayoría; cede ante sus intenciones, deseos e instintos a medio revelar o, más bien, los anticipa y prevé." En opinión de Tocqueville eran las costumbres del pueblo norteamericano las que lo moderaban. Por eso, cuando se trataba de interpretar el alcance del poder federal, Jackson tomaba partido "en contra de sí mismo". Trataba entonces de borrarse y disminuirse (Tocqueville, 1969: 393). Eso era así, porque para Tocqueville el gobierno federal se debilitaba cada día más en respuesta al sentir popular. Creía por ello que las condiciones sociales prevalecientes limitarían efectivamente el riesgo de despotismo. Sin embargo, este análisis parece ingenuo. Como señala Brogan, Tocqueville no vio el papel que el propio Jackson había tenido en la manufactura de esa mayoría que supuestamente lo esclavizaba (Brogan, 1981: 365). En efecto, Tocqueville, "no parece darse cuenta de que si bien Jackson deliberadamente debilitó al gobierno federal vis a vis los estados, de igual forma fortaleció deliberadamente a la presidencia frente al resto del gobierno federal. Van Buren heredó de Jackson una efectiva y formidable máquina política así como una presidencia rejuvenecida" (Brogan, 1981: 365). De la misma forma, Tocqueville no fue capaz de descifrar el significado del vínculo entre la presidencia y el sistema de partidos" (Brogan, 1981: 367). Jackson atacó vigorosamente la idea de que el poder legislativo era el representante del pueblo. La presidencia era un poder autónomo que podía formular su propia interpretación de la constitución, una interpretación que no era menos válida ni legítima que la de los jueces. Los tres poderes eran así coiguales: "la opinión de los jueces no tiene más autoridad sobre el Congreso que la opinión del Congreso sobre los jueces y a ese respecto el Presidente es independiente de ambos" (Jackson, cit. por Brogan, 1981: 368). Tiene razón Brogan cuando afirma que esta doctrina, llevada al extremo, no sólo subvierte el principio de la revisión constitucional (judicial review) establecido en el fallo de la Suprema Corte Marbury v. Madison, sino que haría irrelevante una constitución escrita. Había en Jackson un potencial de usurpación, no sólo en su temperamento, "sino en las doctrinas que proponía" (Brogan, 1981: 368).

Sin embargo, el aspecto más original de la presidencia de Jackson fue el carácter tribunalicio que le confirió al presidente. Creía que éste era el representante directo del pueblo norteamericano (Brogan, 1981: 369). Y esta idea sí es precursora del imaginario populista. Para Jackson el elemento formalmente democrático, es decir el Congreso, estaba plagado de faccionalismo y por ello era incapaz de hablar por el pueblo en su conjunto. En cambio, el presidente sí podría hacerlo. Lo que le daría realidad y sustancia a esta pretensión tribunalicia sería un partido político. Jackson lo entendió y procedió a crear uno.

¿Qué importancia tiene todo esto? Entre el demagogo tradicional y el presidente institucional había un espacio intermedio, el del líder populista — como Jackson - que Tocqueville no pudo aquilatar apropiadamente. Sin un análisis correcto del liderazgo y la organización política no puede haber una teoría certera del populismo. Los liderazgos populistas no podrían tener, de acuerdo con Tocqueville importancia autónoma. Podría haber ciertamente despotismo, pero se trataría del despotismo de la sociedad sobre sí misma. Era eso - un fenómeno nuevo- o la vieja demagogia. Analíticamente un líder populista no 
sería sino el reflejo de la sociedad que lo produjo y sin importancia teórica propia. En el caso de Francia, Tocqueville verá en 1848 un fenómeno social nuevo: masas proletarias movidas por ideas radicales y subversivas, pero en los liderazgos lo que verá será poco original: demagogia del más puro estilo.

\section{La Revolución de 1848: el político populista como aprendiz de mago}

Si Tocqueville creía que las condiciones sociales para el despotismo no estaban dadas en los Estados Unidos durante la era de Jackson, la cosa era muy distinta en Europa en las vísperas de la revolución de 1848. Si en América se exageraban los riesgos para la libertad, en Francia ocurría lo contrario: los políticos no avizoraban la tormenta que se cernía sobre ellos. En sus memorias consignó el ambiente, las costumbres y las pasiones de ese tiempo tumultuoso.

Los Souvenirs pueden ser leídos en parte como un estudio del temperamento de los actores que tuvieron un papel clave en la Revolución de 1848. "Quiero", escribió Tocqueville en 1850, "descubrir los motivos secretos que nos mueven a mis amigos y a mí mismo a la acción” (Tocqueville, 1992: 4). En cierta forma, el estudio del liderazgo y el carácter de los hombres políticos que está ausente en la Democracia en América encuentra aquí un campo fértil para desplegarse. Para Tocqueville las condiciones sociales, las costumbres, se habían transformado peligrosamente durante los últimos años de la Monarquía de Julio. Por una parte había tenido lugar un fermento en los trabajadores y por el otro las clases dirigentes no habían estado a la altura de la circunstancias. Eso fue lo que públicamente dijo en un profético discurso en la Cámara de Diputados el 27 de enero de 1848: “...se dice que no hay peligro porque no hay motín y que nos hallamos lejos de la revolución debido a que no hay un desorden visible en la superficie de la sociedad. Caballeros, déjenme decir que pienso que están equivocados. Cierto, no hay desorden en la actualidad, pero el desorden ha penetrado profundamente en las mentes de los hombres. Vean lo que ha ocurrido entre las clases proletarias las cuales, me doy cuenta, están apaciguadas por el momento. Es cierto que ahora no son víctimas de lo que podríamos llamar apropiadamente pasiones políticas de la manera en la que lo fueron en el pasado, pero ¿no se han dado cuenta de que sus pasiones han mutado de lo político a lo social? ¿No ven que entre ellas se van extendiendo gradualmente opiniones e ideas que propenden no solamente al derrocamiento de tal o cual ley, tal o cual ministro o incluso tal o cual gobierno, sino más bien al derrocamiento de la sociedad, quebrando la base sobre la que ahora descansa? ¿No escuchan lo que ellas dicen cotidianamente? ¿No las escuchan repetir constantemente que la gente por encima de ellas es incapaz e indigna de gobernarlas? ¿Que la división de la propiedad en el mundo hasta ahora es injusta? ¿Que la propiedad descansa sobre bases de inequidad? ¿Y no se dan cuenta de que cuando esas opiniones se enraícen y extiendan, penetrando profundamente en las masas, tarde o temprano tendrán que conducir a la más terrorífica de las revoluciones?” (Tocqueville, 1992: 13).

Las clases dirigentes, pensaba Tocqueville, dormían incautas sobre un volcán activo, arrullándose con canciones de cuna. La situación social las había rebasado. De ahí que pensara que las reformas legislativas y legales serían insuficientes. "Los grandes eventos", contendía, "no emanan del mecanismo de las leyes sino del espíritu mismo del gobierno. Conserven esas leyes si quieren... pero por el amor de Dios cambien el espíritu del gobierno porque, repito, es ese espíritu el que los está conduciendo al abismo" 
(Tocqueville, 1992: 15). ¿Qué, exactamente, le reclamaba Tocqueville a sus pares? Ciertamente la miopía política, pero había algo más, una incapacidad para leer adecuadamente el horizonte social. El discurso fue recibido por las risas de la mayoría partidaria del gobierno. En el retrato crítico que Tocqueville pinta de Luis Felipe está consignada esa incapacidad. Las élites tenían un apetito natural por el poder y poseían una ambición mediocre, que no las llevaba a hacer grandes cosas y tampoco las contentaba. Uno de los fracasos de las clases dirigentes había sido no abrir a tiempo y de manera ordenada la participación política. En efecto, el voto censitario durante la Monarquía de Julio significaba que el "país legal", como lo llamó Guizot, fuera minúsculo: existían menos de un cuarto de millón de electores en un país de más de treinta millones de habitantes (Tocqueville, 1992: 10). Cuando finalmente se propusieron extender la franquicia era ya demasiado tarde.

Tocqueville había identificado un cambio en las condiciones sociales que amenazaba con trastornar el orden establecido. Aquí es donde podemos encontrar algo así como un análisis del político populista. Conviene hacer un recuento de la situación política que precedió a la Revolución de 1848. Por años, el gobierno de Luis Felipe resistió las demandas de la oposición para llevar a cabo una reforma electoral y parlamentaria. Ello llevó a la protesta. El gobierno combatió la agitación política promulgando una ley que limitaba las asambleas públicas. La oposición respondió transformando las reuniones políticas en convites, exentos por tanto de la ley en cuestión. Los ágapes comenzaron en París el 9 de julio de 1847 y se repitieron en otras partes del país entre 1847 y 1848. La campaña de los banquetes estaba programada para terminar con un gran convite en París que se llevaría a cabo el 22 de febrero de 1848. Toda la oposición participó en la organización de la campaña. Sin embargo, los radicales, cuyo líder era Ledru-Rollin, tuvieron preponderancia en ella. Esto resultó en una radicalización del discurso político, cada vez más republicano. El resto de la coalición de oposición no pudo contener ese proceso.

En los meses que precedieron a la revolución Tocqueville políticamente estaba en la oposición, entre dos grupos de izquierda: la dinástica de Odilon Barrot y la de centro-izquierda lidereada por Louis Adolphe Thiers. Ambas facciones habían formado una alianza y Barrot se había involucrado activamente en la organización de los banquetes, mientras que Thiers había mantenido cierta distancia. Thiers, acusaba Tocqueville, se había quedado tranquilamente en París rodeado de sus amigos mientras que Barrot se había pasado tres meses yendo y viniendo por todo el país dando largos discursos en cada localidad en la que paraba (Tocqueville, 1992: 20). Como un miembro independiente de la oposición, Tocqueville había sido invitado a unirse a la aventura de la campaña de los banquetes. Se había rehusado. "La razón principal que me detenía", aducía, "era una que me pasaba explicando a todo aquel que pretendía arrastrarme a los mítines: 'por primera vez en dieciocho años', les decía, 'van a hablarle a la gente y a buscar apoyo fuera de la clase media; si no tienen éxito en excitar la agitación popular (que me parece el resultado más probable), se harán ustedes todavía más odiosos a los ojos del gobierno y de la clase media, la cual apoya mayoritariamente al gobierno y de esa manera reforzarán a la administración que desean tirar. Si, en cambio, tienen éxito en iniciar una agitación popular, ustedes no tienen más idea que yo sobre dónde los conducirá” (Tocqueville, 1992: 20). Contra lo que creía Tocqueville en un inicio, el segundo escenario se hizo realidad. Conforme avanzaba el movimiento hasta los líderes comenzaron a sentirse ansiosos. Beaumont, que se había metido de lleno en la aventura de los banquetes le escribió que en el país la agitación había superado no sólo sus expectativas sino los deseos de quienes la habían comenzado. Incluso habían comenzado a trabajar para apaciguar los ánimos desatados. Asustados, trataban de encontrar alguna forma de cancelar 
el último ágape en París y no querían continuar la campaña una vez que las cámaras se hubieren reunido (Tocqueville, 1992: 21). Sin embargo, las cosas se les habían ido de las manos y no pudieron evitar que se tomara la decisión de llevar a cabo el último banquete. No podían ya retroceder y desvincularse de la empresa. El gobierno, por su parte, endureció su posición pues esperaba provocar un desenlace que destruyera al movimiento de oposición. De esta manera, "ambos lados se apuraban hacia el abismo común y lo alcanzaron sin siquiera percatarse adónde era que se dirigían” (Tocqueville, 1992: 21).

Los líderes populistas eran aprendices de mago, que no tenían cabal conciencia de lo que estaban haciendo. Curiosamente, para Tocqueville los líderes auténticamente radicales en la Cámara no se engañaban de la misma manera. En efecto, "la única gente en París que estaban verdaderamente preocupada en ese entonces eran los líderes radicales y aquellos lo suficientemente cercanos a la gente y al partido revolucionario para saber qué era lo que pasaba. Tengo razones para creer que la mayoría de ellos temía los problemas por venir, tal vez porque para ellos las pasiones del pasado eran tradiciones, no sentimientos. $\mathrm{O}$, tal vez, porque se estaban acostumbrando a un estado de cosas en el cual, a pesar de maldecirlo tan frecuentemente, habían hallado una posición. $\mathrm{O}$, tal vez, porque dudaban del éxito. $\mathrm{O}$, más probablemente, porque teniendo una mejor idea de sus aliados y conociéndolos bien, temían el momento decisivo de la victoria; de lo que le deberían a esos aliados" (Tocqueville, 1992: 23-24).

El problema de la política populista era que en buena medida era impredecible. Así, "una de las características más extrañas de esta singular revolución es que el incidente que la desató fue producido y casi deseado por aquellos que serían derrocados del poder y fueron sólo los futuros vencedores quienes la previeron y temieron" (Tocqueville, 1992: 24). La crisis fue el resultado de la obstinación del rey por impedir el banquete de París. Sus promotores eran hombres animados por pasiones "ciegas" u "hostiles", diría en el discurso de inauguración de sesiones de la cámara de diputados. Cien miembros de la oposición, contrariados, reaccionaron afirmando el derecho de reunión. Al acusar al gobierno de violar la constitución no se percataban, afirmaba Tocqueville, de que hacían un llamamiento no intencional a las armas. Poco tiempo después la olla política estalló y se desató el movimiento revolucionario. En la Cámara los moderados fueron desplazados por el partido radical que los había presionado por meses. Muchos de los líderes de ese partido no eran los parlamentarios (cuyas cabezas se habían enfriado un tanto), sino hombres jóvenes y osados que agitaban en la prensa demagógica. El programa para el banquete de la discordia fue publicado por los diarios el 20 de febrero. En él se hacía un llamamiento a las escuelas y a la Guardia Nacional para que asistieran como cuerpos. Ante ello, el gobierno que había decido tolerarlo a regañadientes y llevar a sus organizadores a tribunales, cambió de opinión y anunció que lo proscribía y que impediría su celebración por la fuerza. Y fue esa declaración la que dio inicio a las hostilidades (Tocqueville, 1992: 26-27). La oposición moderada se había opuesto al programa como fue publicado, pero había sido rebasada y desplazada por sus compañeros de ruta radicales que habían tomado el control del movimiento. Los moderados se enteraron del programa, como todos, por la prensa matutina parisina. La trampa populista se había cerrado. Barrot, un crítico de primera línea del programa, no se atrevió a desautorizarlo por miedo a ofender a quienes, hasta ese momento, habían marchado junto a él. Llevado por la inercia de los acontecimientos, endureció su posición y exigió en la cámara el juicio político de los ministros. A su vez, los líderes del partido radical, quienes pese a todo consideraban una revolución prematura y por ello deseaban evitarla, se vieron obligados a darle tonos revolucionarios a su discurso para distinguirse de sus aliados de la izquierda dinástica de Barrot. Los moderados, a pesar de no querer más 
banquetes, no pudieron dar marcha atrás por temor a dar la impresión de que cedían ante las amenazas del gobierno. Para terminar el cuadro, los conservadores que en general creían que era necesario hacer grandes concesiones y estaban listos para hacerlas, fueron llevados por la violencia de sus adversarios y por la beligerancia de algunos de sus líderes a endurecerse y cerrar filas. Negaron el derecho de reunión incluso en eventos privados y cerrados (Tocqueville, 1992: 28).

Una vez desatada la crisis política el fenómeno político que Tocqueville observó fue el de la demagogia revolucionaria. Y de eso había bastante en la historia reciente de Francia. En la guerra civil hay que tomar partido y Tocqueville lo hizo en consecuencia. De los revolucionarios diría: "ha habido revolucionarios más dañosos que aquellos de 1848, pero dudo que haya algunos más estúpidos" (Tocqueville, 1992: 96). La crítica de la demagogia es fulminante. Los revolucionarios de 1848, "siguiendo los ejemplos del pasado sin comprenderlos imaginaron crédulamente que el convocar al pueblo a la vida política era suficiente para ganárselo para su causa y que para hacer a la República popular era suficiente darles derechos, pero no beneficios. Olvidaron que sus predecesores al mismo tiempo que le dieron a cada campesino un voto abolieron el diezmo, el trabajo no voluntario (corvée) y otros privilegios señoriales y dividieron las tierras de los nobles entre sus antiguos siervos, mientras que no había nada similar que ellos pudieran hacer. Al establecer el sufragio universal pensaron que estaban convocando al pueblo a apoyar la revolución en tanto que lo único que estaban haciendo era armarlo en contra suya" (Tocqueville, 1992: 97).

Tocqueville sabía cuál era su posición en el conflicto. Era ya un partisano en la guerra civil. Se convenció rápidamente de que no habría esperanza de contener de manera gradual y pacífica los ímpetus de la revolución de febrero. Sólo podría ser detenida súbitamente, en una gran batalla que tendría lugar en París. La conflagración le parecía inminente e inevitable y creía que se debía aprovechar la oportunidad para comenzarla (Tocqueville, 1992: 99). Como un parlamentario electo en las primeras elecciones con sufragio universal celebradas poco después de la caída de la monarquía de Julio, Tocqueville tenía un credo político claro. Apoyaría a la república frente a la insurrección popular que la amenazaba. Escribiría: "no tenía causa que defender más que la libertad y la dignidad humana. Mi único plan era proteger las leyes antiguas de la sociedad de los innovadores utilizando la nueva fuerza que el principio republicano podría darle al gobierno, hacer triunfar la clara voluntad del pueblo de Francia sobre las pasiones y los deseos de los proletarios de París y, de esta manera, conquistar la demagogia a través de la democracia" (Tocqueville, 1992: 105-106).

\section{Conclusión}

Una estampa retrata a Tocqueville. En los fragorosos días de la insurrección popular una verdulera le cierra el paso con su carreta y se lanza contra el aristócrata con tal frenesí que éste tuvo dificultad para defenderse del ataque. "La expresión horrible y repulsiva del rostro de la mujer, que reflejaba las pasiones demagógicas y la furia de la guerra civil, me puso a temblar" (Tocqueville, 1992: 145). El quiebre de la más elemental civilidad reinaba en todos los campos. En el seno del proletariado, "el espíritu de la insurrección circulaba de principio a fin en esa vasta clase y en todas sus partes, como sangre en el cuerpo; llenaba tanto aquellos lugares en donde no se combatía como los campos de batalla y había penetrado en nuestras casas, alrededor de nosotros, por encima y por debajo de nosotros. Incluso en aquellos lugares 
donde creíamos que éramos los amos reptaban enemigos domésticos; era como si una atmósfera de guerra civil envolviera todo París" (Tocqueville, 1992: 142).

Sin embargo, el fenómeno de la guerra civil no es el populismo. En cierta forma, la revolución de 1848 fue el resultado de la política demagógica y temeraria de todos los actores involucrados. La oposición moderada había jugado al aprendiz de mago con las pasiones populares y el resultado había sido catastrófico. Habían terminado por ser devorados por esa fuerza que desataron. Con lo interesante que resulta, este episodio no refleja las claves de la razón populista. Lo más parecido que produjo 1848 fue el cesarismo de Luis Napoleón Bonaparte, que confirmaría los temores de Tocqueville respecto al "despotismo de uno solo": su golpe de estado terminó con la Segunda República. En términos generales, las herramientas conceptuales con las que Tocqueville analizó a la revolución de 1848 son convencionales. Era un capítulo nuevo de una vieja historia. No era así con el caso norteamericano. Ahí estaban los atisbos de algo distinto al despotismo de un solo hombre. El populismo le pareció a Tocqueville, en todo caso, un epifenómeno de la sociedad democrática, una de sus feas manifestaciones. Era, creía, la encarnación de un principio general -la tiranía de la mayoría - en un líder político concreto: Jackson. El potencial divisivo -que en algún grado asemeja a la lógica binaria de la guerra civil- del populismo no fue comprendido a cabalidad. Tenía razón al aducir que Jackson no era, ni sería, César, ni Napoleón, ni siquiera Luis Napoleón. Esos tres hombres utilizaron el fervor popular para destruir el arreglo político existente y volverse amos. Pero que Jackson no orquestara un 18 Brumario no lo hacía menos peligroso para la democracia. Una misma sociedad, regida por las pasiones igualitarias, había encumbrado a dos militares de muy distinta calaña: Washington y Jackson. Estos hombres no eran meros epifenómenos de la sociedad democrática. Lo que hicieron o dejaron de hacer tuvo enormes consecuencias para la sociedad que se estaba construyendo. Con lo agudo que fue Tocqueville no discernió el germen de un nuevo mal que se gestaba en el seno de ese nuevo mundo regido por la democracia.

\section{Referencias}

Aguilar Rivera, José Antonio. 2013. Latin American political ideologies. En The Oxford handbook of political ideologies, editado por Michael Freeden y Marc Stears. Oxford: Oxford University Press.

- - 1981. Tocqueville and the American presidency. Journal of American Studies, 15 (3): 357-375.

Brogan, Hugh. 2006. Alexis de Tocqueville. Londres: Profile Books.

Jardin, André. 1998. Tocqueville. A biography. Baltimore: Johns Hopkins University Press. Laclau, Ernesto. 2006. La razón populista. México: Fondo de Cultura Económica.

Müller, Jan-Werner. 2016. What is populism?. Filadelfia: University of Pennsylvania Press.

Ochoa, Paulina. 2015. Power to whom? The people between procedure and populism. En The promise and perils of populism. Global perspectives, editado por Carlos de la Torre. Lexington: University of Kentucky Press, 59-90.

Richter, Melvin. 2007. Tocqueville on threats to liberty in democracy. En The Cambridge companion to Tocqueville. Editado por Cheryl Welch. Cambridge: Cambridge University Press, 245-275.

- - 1988. Tocqueville, Napoleon and Bonapartism. En Reconsidering Tocqueville's Democracy in America. Editado por: Abraham Eisenstadt. New Brunswick: Rutgers University Press. 
- Revista de Ciencias Sociales y Humanidades. ISSN-P: 0188-9834 ISSN-E:2395-8669.

Schleifer, James. 1987. Cómo nació La democracia en América de Tocqueville. México: Fondo de Cultura Económica.

Tocqueville, Alexis de. 1969. Democracy in America, traducida por George Lawrence. Nueva York: Perennial.

- - 1978. La democracia en América. México: Fondo de Cultura Económica.

- - 1992. Recollections. The French revolution of 1848. New Brunswick: Transaction.

-----. 2004. El Antiguo régimen y la Revolución. Madrid: Alianza. 